Article

\title{
University Endowment Committees, Modern Portfolio Theory and Performance
}

\author{
Mimi Lord \\ Weatherhead School of Management, Case Western Reserve University, Cleveland, OH 44106, USA; \\ mimi.lord@case.edu
}

Received: 14 August 2020; Accepted: 28 August 2020; Published: 3 September 2020

\begin{abstract}
University endowments with broad portfolio diversification have been correlated with performance, but committees' decision-making process has received relatively little attention. This study is unique in postulating that the committee's learning commitment and open-mindedness are significant contributors to a decision process that is based on the principles of Modern Portfolio Theory (or, simply, Portfolio Theory). The use of Portfolio Theory as a decision-making framework leads to greater portfolio diversification, which, in turn, leads to higher risk-adjusted returns. This study also demonstrates that greater committee expertise across multiple asset classes contributes to more diversified portfolios.
\end{abstract}

Keywords: portfolio theory; portfolio diversification; open-mindedness; learning commitment; investment performance; decision process; group norms; diversity of expertise

\section{Introduction}

Starting with Harry Markowitz in the early 1950s, studies in finance have demonstrated how diversified investment portfolios contribute to risk-adjusted performance (Markowitz 1952, 1959; Rubenstein 2006; Fabozzi et al. 2007; Elton et al. 2010). Although studies in behavioral finance have explored investor characteristics and behaviors that affect their personal portfolios (Kahneman and Tversky 2000; Thaler 2005; Barber and Odean 2008; Goetzmann and Kumar 2008; Statman 2010), relatively little is known about group behaviors or norms that affect portfolio allocations and performance for institutional investment portfolios (such as pensions, educational funds, and other charitable funds).

To augment the literature, the author explores how characteristics and norms of decision-making committees, typically consisting of volunteers, affect portfolio diversification and risk-adjusted performance of U.S. university endowment portfolios. Specifically, this study examines how the diversity of investment expertise among committee members, in conjunction with norms of a learning commitment and open-mindedness, contribute to a decision-making process that influences portfolio diversification and performance. The selection of these particular variables was informed by studies outside of the investment industry regarding group decision-making (Janis 1972; Amason 1996; Forbes and Milliken 1999), and the author's interviews of endowment representatives on campuses (Lord 2014a).

Markowitz's Modern Portfolio Theory is proposed as the decision-making framework, measured by a scale developed by the author and endorsed by Mr. Markowitz. The committee's use of the theory is proposed as an intermediary of the effect of committee characteristics and norms on portfolio diversification. Diversification, in turn, is shown to have a direct effect on risk-adjusted performance.

This study focuses on the investment committee since it is the body that establishes investment goals and typically sets the asset allocation policy for the endowment. Research within the university endowment domain has found that investment committee members' experience on other boards and 
their business background are correlated with the degree of diversification of the endowment portfolio (Brown et al. 2011). The current study, however, is more specific about the committee members' background, focusing on the degree to which members have expertise in a variety of asset classes, such as domestic and international equities, fixed income, and a range of alternative investments.

Annual studies of college and university endowments by the National Association of College and University Business Officers (NACUBO 1990-2008) demonstrate a positive correlation between size and performance. Large endowments, it is argued, have greater resources to hire talented investment professionals and greater access to top managers, particularly in alternative asset classes (Lerner et al. 2008). Those researchers also found that performance is highly correlated with the academic quality of the student body, as measured by SAT scores. SAT scores may serve as a proxy for the overall skill of the university's administration, the wealth and connections of the alumni, and the prestige of the university brand. Since committee members are often drawn from alumni, their academic abilities may contribute to better decision-making processes and outcomes (Lerner et al. 2008).

The current study, while recognizing the value of factors mentioned above, differs from other university endowment research in its focus on the inner-workings of the committee, and particularly with regards to group norms that affect how members value the importance of continual learning and how they use open-minded dialogue and Portfolio Theory principles to help make asset allocation decisions.

Outside of the university endowment arena, a broad study of mutual fund performance (Bär et al. 2011) found that team-managed funds, as contrasted with single-manager funds, had more diversified portfolios and moderate performance. Single-manager funds tended to have more concentrated portfolios and "extreme" performance (both superior and inferior) than team-managed funds. In contrast, none of the university endowments in the current study has a single manager. Moreover, team-led managers of mutual funds typically have different goals and constraints than university endowment committees, thus influencing their allocations differently.

Understanding factors related to portfolio performance is critical for college and university leaders since the endowment's returns can profoundly affect the amount of student financial aid, administrative staff size, facilities maintenance, programming, and mix of tenure-track and adjunct faculty (Brown et al. 2010). Investment performance of university endowments has taken on added significance due to recession-induced declines in financial markets, donor giving, and state allocations to higher education. The author employs risk-adjusted returns as the dependent variable, rather than absolute returns, in order to make performance comparisons irrespective of differing goals and constraints.

Modern Portfolio Theory, referred to hereafter as simply as Portfolio Theory, is based on mean-variance analysis (Markowitz 1952, 1959), and provides a framework for constructing portfolios that balances the twin goals of performance and risk management. Specifically, the theory posits that diversification promotes efficient portfolios that either: (a) provide greater returns given a specified risk level; or (b) reduce risk for a specified level of return. A number of software programs have been developed to help investors optimize the risk-return profile of their portfolios, with recommended asset allocations given their goals and constraints.

University endowment portfolios have become increasingly diversified in recent years across geographic regions and asset classes, as shown in Table 1.

As recently as 1993, the average U.S. endowment participating in the annual survey by NACUBO (1990-2008) had allocated $87 \%$ of its portfolio to traditional asset classes of fixed income and publicly-traded equities (U.S. and international), $9 \%$ to cash and "other," and only $4 \%$ to alternative investments defined as hedge funds, private equity, real estate, venture capital and natural resources. By fiscal year-end 2008, the average allocation to alternative investments had grown to $23.7 \%$ with hedge funds claiming over half of the alternative allocation. Other notable changes over the 15 years are larger allocations to international equities (with smaller allocations to U.S. equities) and smaller allocations to fixed income. 
Table 1. Shifts in University Endowment Asset Allocations, 1993-2008 (Percentages of Equal-weighted Endowment Portfolios).

\begin{tabular}{cccccc}
\hline Asset Class & $\mathbf{1 9 9 3}$ & $\mathbf{2 0 0 8}$ & Asset Class & $\mathbf{1 9 9 3}$ & $\mathbf{2 0 0 8}$ \\
\hline U.S. Equities & $48.1 \%$ & $34.9 \%$ & Hedge Funds & $0.7 \%$ & $12.9 \%$ \\
International Equities & $4.2 \%$ & $17.0 \%$ & Venture Capital & $0.2 \%$ & $1.1 \%$ \\
U.S. Fixed Income & $33.6 \%$ & $17.6 \%$ & Private Equity & $0.6 \%$ & $3.3 \%$ \\
Non U.S. Fixed Income & $1.3 \%$ & $1.7 \%$ & Natural Resources & $0.3 \%$ & $2.2 \%$ \\
Real Estate (public) & $0.0 \%$ & $1.3 \%$ & Cash & $7.3 \%$ & $3.9 \%$ \\
Real Estate (private) & $1.6 \%$ & $2.9 \%$ & Other & $2.0 \%$ & $1.5 \%$ \\
\hline
\end{tabular}

Note: NACUBO Endowment Studies, 1993-2008. Slight changes have occurred in asset classifications over the years. For example, the 2008 study contained a category called Global Fixed Income which was not listed in the 1993 study. We have included it in Non U.S. Fixed Income for 2008, although it likely contains both international and U.S. bonds.

Asset allocations differ remarkably by the size of the portfolio: in 2008, the largest endowments (those with portfolios greater than $\$ 1$ billion) had allocated $48 \%$ to alternative investments, whereas the smallest endowments (less than $\$ 25$ million) had allocated just $7 \%$ to those investments. Researchers caution against naive imitation of large endowments' asset allocations because alternative assets vary considerably in their performance, and expertise is required to make good decisions (Lerner et al. 2008). Investors also need to be aware of illiquidity risks associated with private investments (Brown et al. 2010). Leibowitz et al. (2010) have demonstrated that the benefits of endowments' allocations to alternative investments are derived predominantly from the additional return expectations rather than from reduced volatility, because the addition of alternative investments has little effect on long-term portfolio volatility.

For decades, investment researchers have attempted to ascertain the relative determinants of performance coming from asset allocation policy, active asset allocation (often called market timing) and selection of specific investments/securities within the asset classes (Brinson et al. 1986; Brinson et al. 1991; Ibbotson and Kaplan 2000; Kritzman and Page 2003). This study, in contrast, examines only on the asset allocation component, and, particularly, the degree to which the portfolio is broadly diversified across a variety of asset classes. While seeking to confirm that broadly diversified portfolios provide higher risk-adjusted returns than do less diversified portfolios, the greater focus in this study is on characteristics and behaviors of the committee in making decisions for more broadly diversified portfolios. The study does not attempt to assess the portions of return resulting from market timing and individual investment/security selection.

In a novel approach, we focus on factors that contribute to greater diversification and stronger risk-adjusted performance among endowments of similar size. This approach provides improved isolation of the factors that are hypothesized to have positive effects on diversification and performance, irrespective of the portfolio's size. Other endowment research has established links between performance and access to top managers, "Ivy League" status, greater alumni giving, higher student-body SAT scores, and the ratio of endowment dollars per student (Lerner et al. 2008). Yet those findings provide few actionable steps for the endowment committee in attempting to improve risk-adjusted performance. The research question posed in this study is a practical one that has not been examined empirically: How can colleges/universities foster an environment that leads to broad diversification and higher risk-adjusted returns of their endowment portfolios? The author argues that selecting investment committee members with expertise in diverse asset classes, promoting an open-minded and learning environment, and employing the principles of Portfolio Theory can play key roles in reaching those objectives, as conceptualized in Figure 1. 


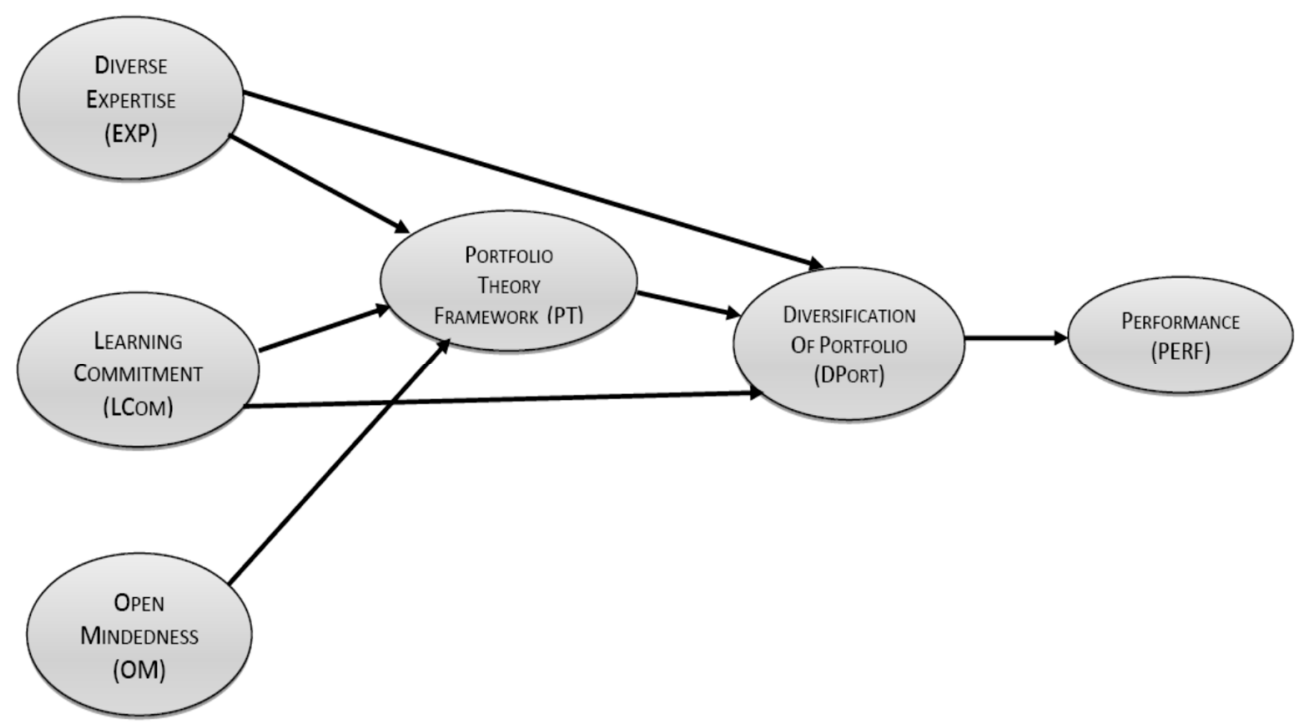

Figure 1. Conceptual Model 1.

\section{Theory and Hypotheses}

\subsection{Diverse Committee Expertise}

Researchers have found that a broad base of knowledge from multiple perspectives provides organizations with a greater ability to access and absorb new knowledge (Cohen and Levinthal 1990; Forbes and Milliken 1999; Zahra and George 2002; Wadhwa and Kotha 2006), greater flexibility and adaptability to environmental change (Lewin and Volberda 1999), increased creativity (Hoffman and Maier 1961), and improved decision quality (Amason 1996). Horwitz and Horwitz (2007) found that teams' task-related diversity, as distinguished from bio-demographic diversity, has a significant positive effect on performance, measured both by quality and quantity. Organizational capability is based on the integration of individuals' specialized knowledge (Grant 1996).

Research on individual investors substantiates the link between investment expertise or "sophistication" and portfolio diversification (Goetzmann and Kumar 2008). Investor characteristics that limit portfolio diversification may include narrow framing of investment decisions (Kahneman and Lovallo 1993; Barberis et al. 2006; Kumar and Lim 2008), risk perceptions (Sjoberg 2000; Weber et al. 2005), and a preference for familiar investments called "home bias" or "domain familiarity" (Tversky and Kahneman 1973; Jemison and Sitkin 1986; Graham et al. 2009). That literature, while focused on studies of individuals, offers support to the view that investment committees with expertise in a variety of asset classes would have broader framing of investment selections and develop more diversified portfolios than teams lacking diverse investment experience. Committees with greater expertise also could be expected to be more familiar with decision frameworks such as Portfolio Theory that promote the use of low- or non-correlated assets and lead to more diversified portfolios. Hypotheses are as follows:

Hypothesis 1. Committee expertise in diversified asset classes will have a positive effect on portfolio diversification.

Hypothesis 2. Greater committee expertise in diversified asset classes will contribute to greater use of Portfolio Theory as a decision-making framework. 


\subsection{Learning Commitment}

Learning theory postulates that knowledge is a key source of competitive advantage (Grant 1996) and organizational learning is recognized as a strategic resource within the resource-based theory (Smith et al. 1996). An organization's commitment to learning is related to the value that it holds toward learning (Sinkula et al. 1997); learning commitment is related to Senge (1990) learning principles and Tobin (1993) expression of "thinking literacy." As stated by Senge (1990), "The organizations that will truly excel in the future will be the organizations that discover how to tap people's commitment and capacity to learn at all levels in an organization."

Learning leads to knowledge, which, when communicated, allows for the organization of activities (Kogut and Zander 1996). Organizational learning may facilitate changes in behavior that lead to improved performance (Slater and Narver 1995). Similarly, learning can facilitate the discovery of superior knowledge and a focused inquiry into how the results of "best practices" can be obtained and transferred (Szulanski 1996). The presence of knowledge led to utilization of knowledge in a study of IT and line managers in large organizations (Boynton et al. 1994). Lastly, the structural aspect of learning posits that an organization's ability to implement behaviors is suggested by the wisdom it accumulates (Garvin 1993). In the author's fieldwork (Lord 2014a), financial officers at top-performing smaller endowments reported that investment committees had engaged in intensive educational sessions about asset classes not previously held in the portfolio before feeling comfortable about making investments in them. Thus, the following hypotheses were made:

Hypothesis 3. The committee's commitment to learning has a positive effect on the use of Portfolio Theory as a framework for portfolio decision-making.

Hypothesis 4. The committee's commitment to learning has a positive effect on portfolio diversification.

\subsection{Open-Mindedness}

Open-mindedness is the ability of the organization to question members' biases and assumptions, and to be open to new approaches (Calantone et al. 2002). Individuals' mental models, which are deeply held beliefs or images of how things work, limit them to familiar ways of thinking and behaving (Day and Nedungadi 1994; Sinkula et al. 1997). Over time, these models may lose their efficacy if they are not questioned and altered (Day 1994; Sinkula 1994). High-performing organizations may benefit from a relatively high level of disagreement as a result of closer inspection of assumptions and alternatives (Janis 1972; Slater and Narver 1995). Thus, open-mindedness is related to cognitive conflict in which diverse perspectives are debated through such techniques as devil's advocacy and dialectical inquiry, resulting in higher-quality decisions (Amason 1996). The process of synthesizing diverse perspectives of team members is considered superior to the individual perspectives alone (Mason and Mitroff 1981; Schweiger and Sandberg 1989).

In group settings involving investment decisions, herding behavior has been evidenced when managers are primarily concerned about their reputations, and can be lessened when the emphasis shifts to profits (Scharfstein and Stein 1990). Financial officers interviewed in the author's qualitative study (Lord 2014a) spoke of the importance of vigorous debate among endowment team members in order to avoid "group think" and situations where a dominant personality could otherwise have undue influence on decisions. Decision-makers frequently differ in their perceptions of the potential risks and returns of various investments. Thus, it seems reasonable that the critical assessment of assumptions, biases, and approaches would lead to better outcomes through the decision-making framework of Portfolio Theory, which incorporates considerations for both risks and returns. Therefore, the following hypothesis:

Hypothesis 5. Open-mindedness among committee members contributes positively to the use of Portfolio Theory framework. 


\subsection{Portfolio Theory}

Portfolio Theory provides a framework for making portfolio decisions that simultaneously considers risks and returns (Fabozzi et al. 2002). The theory holds that, in structuring a portfolio from a set of assets, investors need to estimate: (a) the expected returns of the investments; (b) the expected variance (standard deviation) of returns; and (c) the expected covariance (or correlation) of returns (Michaud and Michaud 2008). Building on Markowitz's theory, the Capital Asset Pricing Model (CAPM) was developed by economists Sharpe, Lintner, and Mossin, and became a standard for measuring professional asset management (Fabozzi et al. 2007).

On the 50th anniversary of the development of Portfolio Theory, Markowitz described it as "a framework to construct and select portfolios based on the expected performance of the investments and the risk appetite of the investors ... " (Fabozzi et al. 2002). He elaborated on the risks of holding highly correlated assets: " ... if any one single investment goes broke it is very likely, due to its high correlation with the other investments, that the other investments are also going to go broke, leading to the entire portfolio going broke" (Fabozzi et al. 2002).

Implementation of Portfolio Theory can be fraught with dangers related to mis-estimations for the inputs of expected returns, variance of returns, and correlations of returns; egregious applications of the theory have occurred because of inappropriate use of historical data (Swensen 2009). Conversely, it can also be very rewarding depending upon the quality of the estimates. The use of mean-variance optimization software requires careful assessment of the estimates going into the analysis and judgment about the ability of the portfolio to achieve the institution's goals (Swensen 2009). Simpler methods, although perhaps not optimal, of diversifying portfolios by equal-averaging across multiple asset classes have been demonstrated to provide significant benefits over under-diversified portfolios (DeMiguel et al. 2009; Gibson 2008).

Although sophisticated quadratic programming can be used in Markowitz portfolio analysis, Gibson (2004) states simply that the key component of Portfolio Theory is that of combining assets with dissimilar patterns of returns: "All other things being equal, the more dissimilarity there is among the asset classes within a portfolio, the stronger the diversification effect, providing investors with not only less volatility, but also greater returns." Thus, the following hypothesis:

Hypothesis 6. The committee's use of Portfolio Theory as a decision-making framework has a positive effect on portfolio diversification.

\subsection{Diversification of Portfolio (Relative to Other Endowments of Similar Size)}

Ample evidence of the benefits of diversification can be found in investment textbooks, financial theory surveys, and financial studies (Rubenstein 2006; Elton et al. 2010). The popular definition of diversification is expressed as "not putting all your eggs in one basket" and the mechanism for the benefits of diversification is that of combining assets with "less-than-perfect positive correlation" of returns (Francis 2010). Industry studies have established positive correlations between portfolio size, diversification, and performance (NACUBO 1990-2008), but, to the best of the author's knowledge, previous research has not empirically tested the relationship between diversification and risk-adjusted performance among endowments of similar size. The relevant hypothesis made is:

Hypothesis 7. Portfolio diversification (relative to other endowments of similar size) has a positive effect on risk-adjusted performance (relative to peers of similar size).

\section{Research Methods}

\subsection{Sample}

The sample was drawn from 650 colleges and universities that have participated regularly in industry surveys about endowment investment practices and for which a minimum of five-year 
(2004-2009) performance data were available. A total of 191 colleges/universities responded to the survey for a response rate of $29 \%$. That number was reduced to 179 , or $27.5 \%$, after eliminating nine cases due to incomplete surveys and three outliers. Sample size of 179 is considered adequate as it comfortably exceeds the minimum recommendation of five observations relative to the number of independent variables (Hair et al. 2010).

Characteristics of respondents, shown in Table 2, revealed that all but four respondents were finance, foundation, or investment officers; two were outsourced Chief Investment Officers and two were investment committee members. On average, respondents have served 11 years in an endowment-related role with the college/university. Respondents were from both public (39\%) and private $(61 \%)$ institutions and the size of endowments spanned all of the categories in the annual NACUBO study, from less than $\$ 25$ million to greater than $\$ 1$ billion. The average endowment size of survey participants as of fiscal year-end 2009 was \$332 million, compared to \$306 million in the 2009 NACUBO-Commonfund Study of Endowments (NACUBO 2009).

Table 2. Demographic Profiles of Respondents and Their Organizations.

\begin{tabular}{|c|c|c|}
\hline Characteristic & $\begin{array}{l}\text { Number of } \\
\text { Respondents }\end{array}$ & $\begin{array}{l}\text { Percent of } \\
\text { Respondents }\end{array}$ \\
\hline \multicolumn{3}{|l|}{ Respondent's Role with College/University } \\
\hline Financial officer involved with the endowment & 175 & $98 \%$ \\
\hline Outsourced Chief Investment Officer & 2 & $1 \%$ \\
\hline Investment Committee Member & 2 & $1 \%$ \\
\hline \multicolumn{3}{|c|}{ Respondent \# of Years in Endowment Role with the College/Univ } \\
\hline Less than or equal to 2.5 years & 22 & $12 \%$ \\
\hline 3 to 5 years & 33 & $18 \%$ \\
\hline 6 to 9 years & 30 & $17 \%$ \\
\hline 10 to 14 years & 34 & $19 \%$ \\
\hline 15 to 19 years & 35 & $20 \%$ \\
\hline Greater than 20 years & 23 & $13 \%$ \\
\hline \multicolumn{3}{|l|}{ Endowment Size } \\
\hline Category 6: Greater than \$1billion & 16 & $9 \%$ \\
\hline Category 5: $\$ 500$ million to $\$ 1$ billion & 20 & $11 \%$ \\
\hline Category 4: $\$ 100$ million to $\$ 500$ million & 56 & $31 \%$ \\
\hline Category 3: $\$ 50$ million to $\$ 100$ million & 30 & $17 \%$ \\
\hline Category 2: $\$ 25$ million to $\$ 50$ million & 25 & $14 \%$ \\
\hline Category 1: Less than $\$ 25$ million & 32 & $18 \%$ \\
\hline \multicolumn{3}{|l|}{ Institutional Funding } \\
\hline Public (State Funded) & 69 & $39 \%$ \\
\hline Private & 110 & $61 \%$ \\
\hline \multicolumn{3}{|c|}{ Number of Voting Members on Investment Committee } \\
\hline Less than or equal to 3 & 4 & $2 \%$ \\
\hline $4-6$ & 64 & $36 \%$ \\
\hline $7-9$ & 84 & $47 \%$ \\
\hline $10-13$ & 22 & $12 \%$ \\
\hline $14-18$ & 4 & $2 \%$ \\
\hline Greater than or equal to 19 & 1 & $1 \%$ \\
\hline \multicolumn{3}{|c|}{ Number of Meetings/Year of Investment Committee over 5-year period } \\
\hline Less than or equal to 3 & 6 & $3.50 \%$ \\
\hline $3-4$ & 99 & $55.60 \%$ \\
\hline $5-8$ & 53 & $29.80 \%$ \\
\hline $9-12$ & 14 & $7.60 \%$ \\
\hline Greater than or equal to 13 & 6 & $3.50 \%$ \\
\hline \multicolumn{3}{|c|}{ \# of Finance/Investment Staff with Significant Investment Experience } \\
\hline 0 & 27 & $15 \%$ \\
\hline 1 & 57 & $32 \%$ \\
\hline 2 & 43 & $24 \%$ \\
\hline 3 & 22 & $12 \%$ \\
\hline $4-7$ & 22 & $12 \%$ \\
\hline $8-12$ & 7 & $4 \%$ \\
\hline $13-20$ & 1 & $0.50 \%$ \\
\hline
\end{tabular}


The investment committees in the sample have played important roles in key decisions concerning the management of the portfolio: $68 \%$ of respondents indicated that the committee made final decisions about hiring/firing managers and $67 \%$ said the committee made the final decision about hiring/firing consultants. Sixty-two percent of respondents indicated that the investment committee made the final decisions regarding policy asset allocations over the five-year measurement period, followed by the governing board of trustees/foundation, 34\%. In response to the question, "Which body had the greatest impact on performance over the 2004-2009 period", responses were distributed more widely: investment committee, $41 \%$; consultant, $25 \%$; staff (such as Chief Investment Officer or Chief Financial Officer), 16\%; outsourced CIO or Investment Management Firm, 13\%; board of trustees/foundation, $3 \%$; and other, $2 \%$.

To determine if the sample was representative of all 650 colleges with five-year performance data in the 2009 NACUBO-Commonfund survey, we conducted an independent samples t-test of the means of the five-year annualized returns. No significant difference was observed between the means $(\mathrm{t}=0.44$; $\mathrm{df}=826 ; p>0.05$ ). The mean return from the NACUBO-Commonfund study was $2.7 \%, \mathrm{~s}=2.8 \%$, while the mean of this sample was $2.6 \% ; \mathrm{s}=2.1 \%$.

\subsection{Data Collection and Screening}

Measures for content validity were assessed using expert opinions of 12 asset management professionals. For internal validity, the author used a pretest to assess the nature of the relationships among the constructs and modified problematic items as necessary. This strategy helped ensure that the measurement scales possessed adequate content validity, while permitting the testing of their psychometric properties (i.e., scale reliability and construct validity).

Empirical data to test the hypothesized relationships were obtained by using an electronic survey. Emails soliciting participation were sent to 650 colleges and universities, all of which had participated in the 2009 NACUBO-Commonfund Endowment Study and/or in previous annual surveys sponsored solely by NACUBO and for which five-year performance data through mid-2009 were available. Emails were addressed to financial officers requesting survey participation by a "key informant:" someone who has regularly attended committee meetings for at least several years and is very knowledgeable about the committee's responsibilities and decision-making practices, as well as the investment experience of committee members. The solicitation email suggested that either the university financial officer most involved with the endowment or the investment committee chair would be an ideal respondent. Three follow-up emails were sent in intervals of approximately 12 days during September and October 2010.

After eliminating incomplete surveys and outliers, missing data on remaining cases were less than $1 \%$ and were replaced with median values for the variable. Although the data were slightly skewed, there were no serious violations of normality assumptions detected. Correlations between factors were all less than 0.60 and all variance inflation factors were below 4.0, indicating a lack of problems with multicollinearity. Homogeneity of variance was tested using Levene's test. As all IVs and mediator were significant, we cannot reject the null hypothesis that the variance of the groups is equal.

\subsection{Measurement}

The questionnaire consisted of 21 items used in scales for the constructs, provided in Appendix A. In addition, respondents were asked to provide their endowment's five-year annualized total return, using the same number they provided in the 2009 NACUBO-Commonfund study. Survey participants were instructed to base their responses over the period covering mid-2004 to mid-2009. That timeframe was chosen since: (1) it was a period of time for which the author gratefully had full access to NACUBO studies (certain data specific to individual universities are not available to the general public); (2) it contained different market environments with periods of both positive and negative endowment performance; (3) it covered a span in which the majority of the author's survey recipients were expected to have been involved with the endowment; (4) it permitted a sufficient number of respondents with five-year performance data in order to conduct meaningful analysis. 


\subsection{Independent Variables}

The scale items for the three independent variables (diverse expertise, learning commitment and open-mindedness) employed a 7-point Likert scale ranging from Very Strongly Disagree to Very Strongly Agree. Both learning commitment and open-mindedness were adapted from existing scales (Sinkula et al. 1997; Calantone et al. 2002). Among the learning commitment items were: "The committee believed learning is a key commodity for long-term success" and "The committee was committed to learning about successful endowment practices." Open-mindedness items included: "Committee members frequently questioned their biases about investing" and "The committee was not afraid to reflect critically on investment-related assumptions it made." Items for diverse committee expertise were informed by extensive interviews from an earlier qualitative study (Lord 2014a), theory (Forbes and Milliken 1999), and pre-testing with investment professionals. Committee expertise items sought to identify whether members had expertise across a broad variety of investments including traditional and alternative asset classes, as well as public and private.

\subsection{Portfolio Theory}

Portfolio Theory is hypothesized as an intermediary variable serving as a decision-making process for portfolio allocations. The development of the Portfolio Theory measure was informed by theory (Markowitz 1952, 1959) and by pretesting with 12 investment professionals. Items inquired about members' consideration of investments' expected returns, variance of returns and correlations of returns when making portfolio decisions. Additional questions included variations of those items, such as: "The committee considered the risk-return characteristics of the overall portfolio when making changes in its composition" and "The committee carefully considered the downside risks of existing and potential investments".

\subsection{Diversification of Portfolio}

Since portfolio diversification and size of portfolio have been linked in previous studies (NACUBO 1990-2008), the measure of portfolio diversification in this study controlled for size by asking for participants' perception of their endowment's degree of diversification relative to the average diversification of peers in their size category in annual industry studies. Size categories in the NACUBO studies are as follows: (1) <\$25 mil; (2) $\$ 25 \mathrm{mil}$ to $\$ 50 \mathrm{mil}$; (3) $\$ 50 \mathrm{mil}$ to $\$ 100 \mathrm{mil}$; (4) $\$ 100 \mathrm{mil}$ to $\$ 500 \mathrm{mil} ;$ (5) $\$ 500 \mathrm{mil}$ to $\$ 1 \mathrm{bil}$; and (6) > $\$ 1$ bil.

Supporting evidence of participants' awareness of other endowments' degree of diversification is based on an $86 \%$ affirmative answer to the following survey question: "Has the committee typically compared your institution with others in the NACUBO and/or NACUBO-Commonfund study over the past several years?" Of the 179 participants in this study, 154 responded "yes", 19 responded "no", and six did not respond.

Three items were used to measure portfolio diversification relative to size peers over the recent 10-year, 5-year, and 1-year periods; response choices ranged from 1-significantly less diversified to 5-significantly more diversified. Although primarily interested in the 5-year period, the author included both a longer and shorter period for a fuller perspective; industry surveys have documented the steady, incremental march toward greater portfolio diversification, both on a total industry level and on the category size level (NACUBO 1990-2008). It is thus logical to assume that participants' perceptions of their endowments' diversification relative to their size peers would be largely consistent over the time periods.

Note that in a related study (Lord 2014b), the author used actual asset allocation data from the 2008 NACUBO study to assess the degree of diversification across asset classes. The significant degree of correlation between that data and the responses in the current study helps to support the validity of using respondents' perceptions of their endowments' relative degree of diversification. 


\subsection{Performance}

For performance measurement, the survey requested annualized total returns of endowments over 1,3,5, and 10-year periods ended fiscal 2009; the 5-year data used in this study were crossed-checked with data in the 2009 NACUBO-Commonfund Endowment Survey. In order to obtain risk-adjusted performance the author divided the five-year annualized return of each endowment by the standard deviation of the annual returns over the five years. Since absolute endowment size has already been linked to performance in industry studies (NACUBO 1990-2008), we chose to measure risk-adjusted performance of each university relative to the risk-adjusted average performance of peers in their own size category. Therefore, both portfolio diversification and risk-adjusted performance are relative measures.

\subsection{Control Variables}

The number of endowment staff with professional investment expertise as well as the absolute endowment size were controlled for since these variables have been linked previously to investment performance (NACUBO 1990-2008).

\subsection{Exploratory Analysis}

An Exploratory Factor Analysis was conducted simultaneously with all items for the latent factors using Principal Axis Factoring with Promax rotation. The Kaiser-Meyer-Olkin measure of 0.904 indicated sampling adequacy for factor analysis. Analysis of initial communalities revealed that all items exceeded the threshold of 0.50 . An unconstrained five-factor model emerged from the extraction process. All five factors had eigenvalues greater than 1.0 and explained $81 \%$ of total variance. The pattern matrix, as shown in Appendix B, revealed that all items loaded highly on their intended factors with minimal cross-loading. Appendix C contains Descriptive Statistics and Appendix D contains the correlation of measures for constructs.

\subsection{Confirmatory Factor Analysis}

Confirmatory Factor Analysis (CFA) was conducted next to validate the initial factors' structure and to assess model fit, which was deemed acceptable ( $\mathrm{cmin} / \mathrm{df}$ of 1.427, GFI of 0.892, CFI of 0.977, PCFI of 0.819 and RMSEA of 0.049 with PCLOSE of 0.537). Three pairs of items were covaried, each within its hypothesized construct, contributing positively to model fit. A chi-square difference test confirmed measurement invariance of two groups (top performers and bottom performers). The CFA diagram is provided in Appendix E. As seen in Table 3, loadings ranged from 0.66 to 0.99 and all were statistically significant at $p<0.001$.

Table 3. CFA Measurement Model Results.

\begin{tabular}{clccccc}
\hline Code & & Construct & Est & S.E. & C.R. & $p$ \\
\hline EXP_1 & $<-$ & Diverse Expertise & 0.864 & 0.065 & 13.356 & $* * *$ \\
EXP_2 & $<-$ & Diverse Expertise & 0.892 & 0.063 & 14.161 & $* * *$ \\
EXP_4 & $<-$ & Diverse Expertise & 0.907 & 0.063 & 14.480 & $* * *$ \\
\hline LC_1 & $<-$ & Learning Commitment & 0.844 & 0.060 & 14.095 & $* * *$ \\
LC_2 & $<-$ & Learning Commitment & 0.948 & 0.056 & 17.073 & $* * *$ \\
LC_3 & $<-$ & Learning Commitment & 0.912 & 0.058 & 15.748 & $* * *$ \\
LC_4 & $<-$ & Learning Commitment & 0.888 & 0.058 & 15.381 & $* * *$ \\
LC_5 & $<-$ & Learning Commitment & 0.946 & 0.055 & 17.053 & $* * *$ \\
\hline OM_1 & $<-$ & Open-mindedness & 0.662 & 0.068 & 9.735 & $* * *$ \\
OM_2 & $<-$ & Open-mindedness & 0.827 & 0.063 & 13.176 & $* * *$ \\
OM_3 & $<-$ & Open-mindedness & 0.866 & 0.061 & 14.306 & $* * *$ \\
OM_4 & $<-$ & Open-mindedness & 0.742 & 0.065 & 11.451 & $* * *$ \\
\hline
\end{tabular}


Table 3. Cont.

\begin{tabular}{clccccc}
\hline Code & & Construct & Est & S.E. & C.R. & $p$ \\
\hline PT_1 & $<-$ & Portfolio Theory & 0.759 & 0.064 & 11.777 & $* * *$ \\
PT_2 & $<-$ & Portfolio Theory & 0.783 & 0.064 & 12.153 & $* * *$ \\
PT_3 & $<-$ & Portfolio Theory & 0.929 & 0.058 & 15.937 & $* * *$ \\
PT_4 & $<-$ & Portfolio Theory & 0.852 & 0.061 & 13.925 & $* * *$ \\
PT_5 & $<-$ & Portfolio Theory & 0.832 & 0.062 & 13.387 & $* * *$ \\
PT_6 & $<-$ & Portfolio Theory & 0.754 & 0.065 & 11.667 & $* * *$ \\
\hline DPORT_1 & $<-$ & Diversification of Portfolio & 0.829 & 0.063 & 13.141 & $* * *$ \\
DPORT_2 & $<-$ & Diversification of Portfolio & 0.987 & 0.057 & 17.215 & $* * *$ \\
DPORT_3 & $<-$ & Diversification of Portfolio & 0.791 & 0.064 & 12.320 & $* * *$ \\
\hline
\end{tabular}

Note: Significance: ${ }^{* * *} p<0.001$.

\subsection{Common Method Variance}

The first test for common method bias used a post hoc procedure suggested by Podsakoff and Organ (1986). Using the principal components factor analysis, evidence of common method bias exists when a single factor emerges from the analysis, or one general factor accounts for the majority of the covariance in the interdependent and dependent variables. Those conditions do not exist in this study's factor analysis. A second test for CMB involved the addition of a marker variable (Lindell and Whitney 2001), which reduced common method bias to $7.3 \%$.

\subsection{Reliability and Validity Analysis}

To assess the measurement model's reliability, discriminate and convergent validity, the author used the composite reliability coefficient (CR), average variance extracted (AVE) and the shared variance (Maximum Shared Variance, MSV, and Average Shared Variance, ASV). Table 4 indicates that the model met the threshold for item reliability $(C R>0.70)$ as well as those for convergent and discriminant validity, both before and after controlling for common method variance (CMV). To estimate the common method variance the author used the correlation between the marker variable and the other factors to recompute the reliability and validity measures shown in Table 4. All of the measurement model's constructs retained their reliability, convergent validity, and discriminate validity even after controlling for common method variance. Internal consistency was confirmed with Cronbach's alpha coefficients all well above 0.7. The measures support the reliability as well as the convergent and discriminant validity of the constructs.

Table 4. Reliability and Validity Tests for Constructs.

\begin{tabular}{|c|c|c|c|c|c|c|c|c|c|c|}
\hline \multicolumn{11}{|c|}{ Reliability and Validity Tests for Constructs } \\
\hline \multirow{2}{*}{ Factor } & \multirow{2}{*}{\multicolumn{2}{|c|}{$\begin{array}{c}\text { Chronbach's } \\
\text { Alpha }\end{array}$}} & \multicolumn{4}{|c|}{$\leftarrow$ Before Controlling for $\mathrm{CMV} \rightarrow$} & \multicolumn{4}{|c|}{$\leftarrow$ After Controlling for $\mathrm{CMV} \rightarrow$} \\
\hline & & & C.R. & AVE & MSV & ASV & CR & AVE & MSV & ASV \\
\hline Diverse Expertise & EXP & 0.935 & 0.92 & 0.80 & 0.35 & 0.23 & 0.89 & 0.72 & 0.34 & 0.20 \\
\hline Learning Commitment & LCom & 0.960 & 0.96 & 0.83 & 0.36 & 0.22 & 0.94 & 0.79 & 0.36 & 0.18 \\
\hline Open-Mindedness & $\mathrm{OM}$ & 0.866 & 0.87 & 0.62 & 0.36 & 0.28 & 0.82 & 0.53 & 0.36 & 0.23 \\
\hline Use of Portfolio Theory & $\mathrm{PT}$ & 0.928 & 0.92 & 0.67 & 0.32 & 0.20 & 0.90 & 0.60 & 0.32 & 0.16 \\
\hline Diversification of Portfolio & DPort & 0.895 & 0.90 & 0.76 & 0.17 & 0.11 & 0.87 & 0.68 & 0.17 & 0.09 \\
\hline \multicolumn{11}{|c|}{ 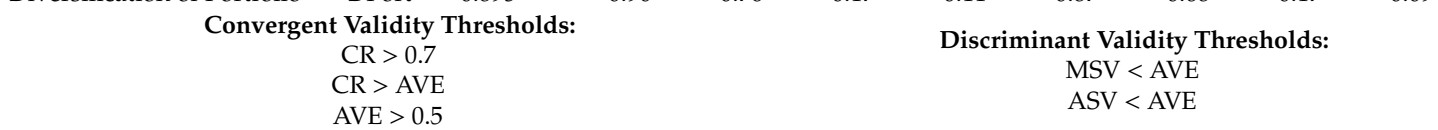 } \\
\hline
\end{tabular}

\subsection{Hypotheses Testing}

Hypotheses were tested using covariance-based structural equation modeling (SEM). SEM is statistical software tool that can simultaneously evaluate multiple variables and their relationships. It can be used for concept and theory development as well as for hypothesis testing (Hair et al. 2014). 
The SEM software used for this study is IBM SPSS AMOS (analysis of a moment structure). Results for the full sample are shown in Figure 2 (before trimming insignificant paths) and also in Table 5, both before and after trimming insignificant paths. The trimmed model has excellent fit with CMIN/DF of 1.11, CFI of 0.996, and RMSEA of 0.025 .

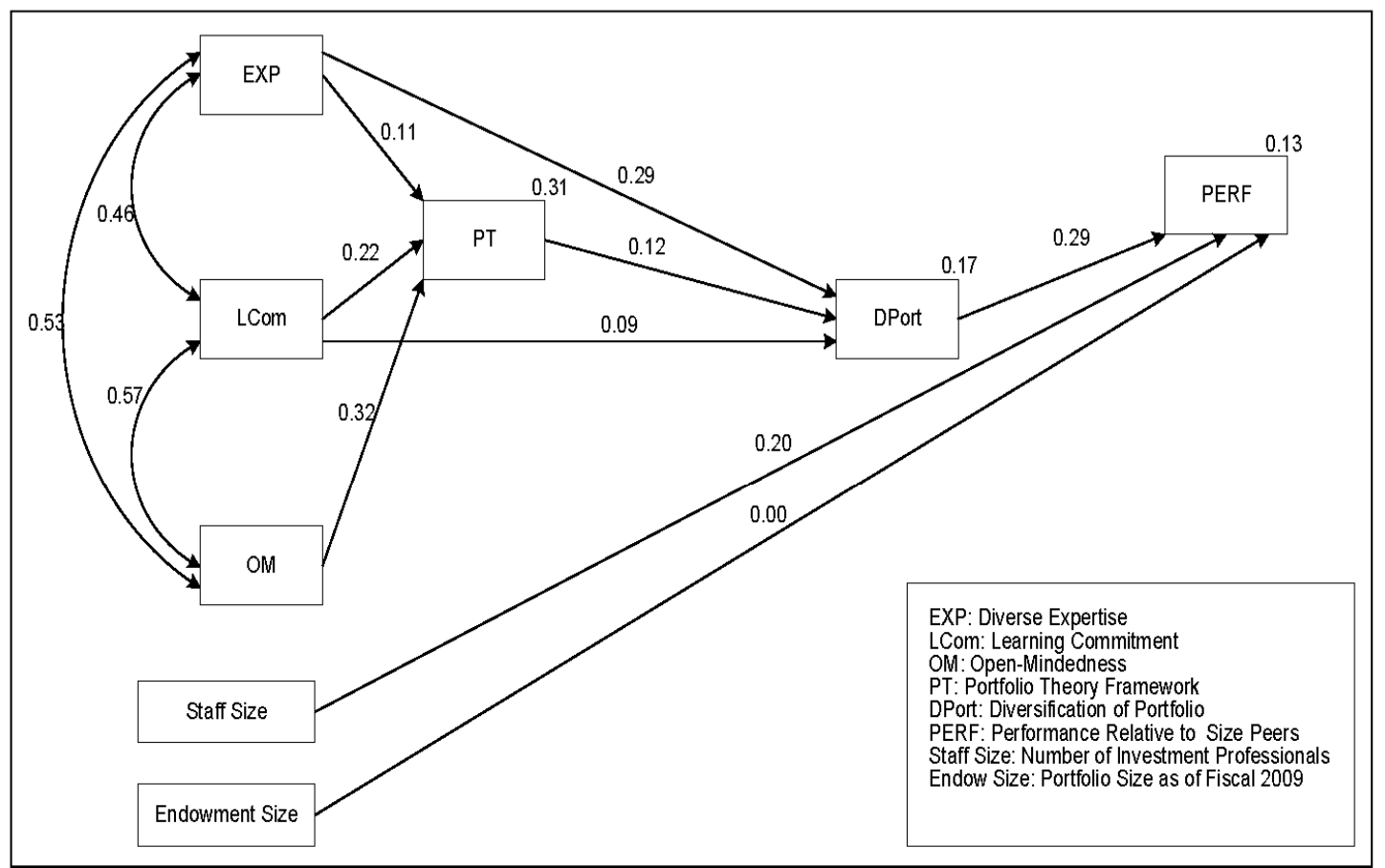

Figure 2. Results of the Hypothesized Model (Standardized Estimates).

Table 5. Results: Hypotheses 1-7.

\begin{tabular}{ccccc}
\hline Structural Paths & $\begin{array}{c}\text { Estimates } \\
\text { (Unstandardized) }\end{array}$ & Critical Ratio & $p$-Value & $\begin{array}{c}\text { Hypothesis } \\
\text { Supported/Not } \\
\text { Supported }\end{array}$ \\
\hline H1: Diverse Exp $\rightarrow$ DPort & Before Trimming Insignificant Paths & & \\
H2: Diverse Exp $\rightarrow$ PT & 0.284 & 3.659 & $* * *$ & Supported \\
H3: LCom $\rightarrow$ PT & 0.118 & 1.535 & 0.125 & Not Supported \\
H4: LCom $\rightarrow$ DPort & 0.175 & 2.860 & 0.004 & Supported \\
H5: OM $\rightarrow$ PT & 0.071 & 1.146 & 0.252 & Not Supported \\
H6: PT $\rightarrow$ DPort & 0.372 & 3.991 & $* * *$ & Supported \\
H7: DPort $\rightarrow$ PERF & 0.112 & 1.471 & 0.141 & Not Supported \\
After Trimming Insignificant Paths (starting with least significant) & Supported \\
\hline H1: Diverse Exp $\rightarrow$ DPort & 0.314 & 4.438 & Supported \\
H3: LCom $\rightarrow$ PT & 0.197 & 3.269 & 0.001 & Supported \\
H5: OM $\rightarrow$ PT & 0.424 & 4.851 & $* * *$ & Supported \\
H6: PT $\rightarrow$ DPort & 0.142 & 2.046 & 0.041 & Supported \\
H7: DPort $\rightarrow$ PERF & 0.238 & 3.273 & $* * *$ & Supported \\
\hline
\end{tabular}

Note: Significance: ${ }^{* * *} p<0.001$. Factor DPort is the abbreviation for "degree of portfolio diversification relative to endowment portolios of similar size." PERF is the performance abbreviation for "risk-adjusted returns relative to the average for the size category."

\section{Results and Discussion}

Hypothesis 1. This hypothesis is supported. This finding has sound logic in that one would expect committee members with expertise in particular asset classes to generally want some representation in the portfolio of those asset classes. This would be particularly the case when the endowment follows a 
policy asset allocation with a long-term horizon. In most instances, the policy asset allocation permits a range of weights in the portfolio for each asset class, and so the committee would have some leeway, if desired, to alter the weight somewhat based on factors such as valuation and economic conditions.

Hypothesis 2. This hypothesis is not supported. Perhaps in many situations, each committee member has expertise in only one asset class and is not accustomed to considering expected returns, variance of returns, and correlations of returns involving the other asset classes.

Hypothesis 3. This hypothesis is supported. Committee members with a commitment to learning, which includes a belief that learning is a key component to success, will devote considerable time and effort to learn about and improve their understanding of principles of portfolio construction. In this model, perhaps the hardest "work" is making estimates about expected returns of the various asset classes, variance of returns, and correlation of returns. Moreover, the estimates need to be revisited at times due to changing valuations and economic conditions, changing weights of each asset class in the portfolio, etc. In a sense, the "commitment to learning" variable also represents a level of diligence and dedication, or, quite simply, a willingness to do the work.

Hypothesis 4. This hypothesis is not supported. There is a modest positive correlation between the two factors, but it is not significant.

Hypothesis 5. This hypothesis is supported. The open-mindedness construct represents a willingness for committee members to continually question their biases and assumptions. It encourages critical reflection and a willingness to express differing opinions. Since the use of Portfolio Theory principles requires making important estimates, it seems reasonable that having an open-minded committee would hash out their views in making these determinations. Note that while Open-Mindedness was not hypothesized to have a direct effect on portfolio diversification, it does, at a minimum, have an indirect effect via Portfolio Theory.

Hypothesis 6 . This hypothesis is supported. While the Portfolio Theory component of estimating returns might influence committee decisions about the weights to assign to each asset class, the other two components (variation of returns and correlation of returns) likely play a bigger role in affecting the diversification of the portfolio. For example, asset classes with sizable return variations might need to be limited to a certain level to avoid making the portfolio riskier than the university desired. Also, asset classes that have significant return correlations may need to be limited to avoid the risks of over-concentration in the behavior characteristics of those asset classes. Those are just two examples of situations where use of Portfolio Theory would result in broader portfolio diversification.

Hypothesis 7. This hypothesis is supported in the final results after trimming the weakest path in the hypothesized model. Considerable research has documented the significant and positive correlation between portfolio diversification and performance, and the significant positive relationship between size and each of those. However, this finding differs from previous ones in that it examines the relationship within each category of portfolio size. Thus, even among portfolios of similar size, broader diversification leads to higher risk-adjusted returns. Note in the top portion of Table 5 that Portfolio Theory does NOT have a significant effect on portfolio diversification before trimming insignificant paths. However, the SEM analysis requires trimming (eliminating) insignificant paths one at a time, starting with the weakest path. The weakest path was that from Learning Commitment to Diversified Portfolio, and once that path was trimmed, the path from Portfolio Theory to Diversified Portfolio became significant.

The control variable for the number of full-time professional investment staff does have a significant effect on the relative performance dependent variable. However, the second control variable-absolute endowment size-does not have a significant effect on the performance of endowments relative to their size category. The author assumes that the performance variable, which measures performance relative to other portfolios in the same size category, already provides a sufficient control for size.

\section{Research Contributions}

This study adds to existing research in multiple ways: 
1. Extending the research on investment committee composition and diversity. A considerable body of research has examined the effects of having decision-making boards diversified by gender, race or ethnic background. A smaller body has looked at board diversity in terms of having representatives of multiple professions, such as lawyers, accountants and financial officers. This study is additive by analyzing the effect of having specialty expertise within the field of investment professionals. This suggests that finer tuning of board diversity may be beneficial in other research settings.

2. Using group norms such as learning commitment and open-mindedness in a new setting. These norms have been used in marketing studies and in certain organizational behavior literature, but this is the first time (to the author's knowledge) that it has been used in an institutional investment domain.

3. Developing a measurement scale for the use of Portfolio Theory as a decision-making process. The scale captures the three key components of estimating investment returns, variance, and correlations of return. The author had the honor of meeting with Professor Harry Markowitz, founder of the theory, in March 2011 and was pleased that he found the construct items to be suitable.

4. Measuring portfolio diversification and performance relative to portfolios of similar size. Research about university endowment performance has long acknowledged the links between diversified portfolios, performance and portfolio size. This study also finds that the performance benefits of broader diversification accrue to smaller portfolios.

5. The use of risk-adjusted portfolio returns instead of absolute returns. Performance data from annual NACUBO studies are expressed in absolute returns, which do not take risk into account. Risk-adjusted returns are generally considered to be preferable in making comparisons between various portfolios with differing objectives.

\section{Practical Contributions}

Practical contributions to university endowment leaders include the following:

1. Demonstrating the value of having committee members with expertise in a variety of asset classes. This will help match the skills available to the skills needed.

2. Developing an atmosphere where continual learning is highly valued and practiced. This not only augments the committee's knowledge, but also the dedication to continual improvement.

3. Encouraging the practice of open-mindedness in investment committee meetings so that differing opinions can be fully vetted, and assumptions can be tested.

4. Supporting the use of Portfolio Theory principles when analyzing various asset classes. This can be expected to improve the risk-reward profile of the portfolio.

5. Professional, paid staff can make significant contributions to performance. Staff may provide valuable functions such as analysis of money managers and specific securities that are beyond the committee's responsibilities. This study indicated that larger staffs have greater contributions to performance than smaller staffs. Understandably, the improvement in performance should be expected to exceed the cost of a larger staff. And, with good reason, the quality of staff should also be considered, not just the number of staff.

\section{Limitations}

Despite its contributions, the study has some notable limitations providing opportunities for future research. First, the measures of committee characteristics and practices were based on key informant assessments that may be biased. Next, the study does not include certain components of return that are well recognized, specifically active (or tactical) asset allocation and investment/security selection. The other key component of return, called policy asset allocation, is roughly represented in the study by the variable "Diversified Portfolio." Policy asset allocation establishes long-term 
allocations within ranges for each asset class. Active asset allocation and investment/stock selection were not included in this study due to inaccessibility to data and complexity.

In addition, numerous other factors that likely contribute to performance-such as criteria and processes for selecting consultants and investment managers-were not included in the study. As indicated earlier, for many endowments the influence of consultants was considered a key factor for performance and it would be useful to gain a better understanding of the nature and effect of that influence. Another important limitation of this study is that it did not analyze the influences of university governing boards other than noting that approximately one-third of respondents indicated that the governing board controls the final decision over asset allocation policy. Further research on the nature of governing board's influence on portfolios appears to be warranted.

Other variables-such as academic quality of students and level of alumni donations-that have been found in other studies to correlate to performance were not controlled for in this study. Those factors may contribute positively to the expertise sought in selecting not only committee members also external consultants and investment managers.

Another limitation is that the study does not account for the fact that different universities may have different goals and objectives for the portfolio. For example, certain endowments are used to support student scholarships and the portfolios need to produce fairly stable performance with above-average income. Other endowments of universities with plans for long-term growth may need to be invested more aggressively. Therefore, while the dependent variable of risk-adjusted returns (relative to other endowments of similar size), is convenient for making comparisons, it likely does not represent the primary objective for many endowments.

Lastly, the direction of relationships cannot be certain. For example, does "greater expertise across a variety of asset classes" lead to "greater portfolio diversification" or does the relationship occur in reverse order? It would seem likely that in the early stages of developing more diversified portfolios, the direction specified in the model would facilitate the understanding of various asset classes in order for the committee to make decisions about adding more asset classes. It is important to note that professional, external consultants also play a key role, not examined in the current study, in explaining various asset classes and their roles in a portfolio. Later on, as the portfolio becomes more diversified and complex, and members rotate off the committee, the selection of new members may include a consideration that they already have sufficient expertise to understand the existing portfolio and, hopefully, to make improvements.

\section{Applicability}

We believe our findings are generalizable across U.S. university endowments; a topic for future research would be assessing their applicability to other institutional investment pools where committees make asset allocation decisions. The independent variables of Diverse Expertise, Learning Commitment and Open-mindedness could be found to lead to better decision-making in any number of board or team settings. They could be used with a variety of other decision-making frameworks and with additional dependent variables.

Funding: This research received no external funding.

Conflicts of Interest: The author declares no conflict of interest.

\section{Appendix A. Constructs, Definitions and Items}

Diverse Expertise (EXP): Committee members' expertise across a broad variety of asset classes and investments.

- Our committee over the 5-year period always included expertise across a broad variety of asset classes. (EXP1)

- Our committee always included expert knowledge in both traditional and alternative asset classes. (EXP2)

- Our committee always included experts in both public and private investments. (EXP4) 
Learning Commitment (LCom): The shared belief that learning is essential for success.

- Investment committee members were in agreement that their ability to learn about endowment management is essential to our success. (LC1)

- $\quad$ The basic values of the committee included learning as key to improvement. (LC2)

- The committee viewed learning as an investment, not an expense. (LC3)

- The committee was committed to learning about successful endowment practices. (LC4)

- $\quad$ The committee believed learning is a key commodity for long-term success. (LC5)

Open-Mindedness (OM): The committee's critical assessment of its assumptions, biases and decisions.

- Committee members frequently questioned their biases about investing. (OM 1)

- Committee members routinely judged the quality of the decisions they made. (OM2)

- The committee was not afraid to reflect critically on investment-related assumptions it made. (OM3)

- Committee members realized that the way we perceive the markets must be continually questioned. (OM4)

Use of Portfolio Theory (PT): The Committee's consideration of principles of Portfolio Theory in making portfolio decisions.

- When making portfolio decisions, the committee routinely considered expected returns of investments. (PT1)

- The committee routinely reassessed expected returns of investments based on changing market conditions. (PT2)

- The committee routinely considered the correlation of returns of existing and potential portfolio holdings. (PT3)

- As part of the portfolio decision-making process, the committee analyzed investments' historical variation of returns. (PT4)

- The committee considered the risk-return characteristics of the overall portfolio when making changes in its composition. (PT5)

- $\quad$ The committee carefully considered the downside risks of existing and potential investments. (PT6)

Diversification of Portfolio (DPort): The degree of endowments' portfolio diversification relative to their size category in annual industry surveys.

- Our endowment's diversification over the SINGLE FISCAL YEAR 2009 relative to our size category was ... (DPort1)

- Our endowment's diversification over the FIVE YEARS ended 2009 compared to our size category was ... (DPort 2)

- Our endowment's diversification over the DECADE ended fiscal 2009 compared to our size category was ... (DPort3)

NOTE: Items in EXP, LCom, OM and PT referred to the 2004-2009 period and were measured using a 7 -point scale $(1=$ very strongly disagree, 7 = very strongly agree). Items for DPort were measured using a 5-point scale ( 1 = significantly less diversified, $5=$ significantly more diversified $)$. 


\section{Appendix B}

Table A1. Pattern Matrix, MSAs and Communalities of Extracted Factors.

\begin{tabular}{|c|c|c|c|c|c|c|c|}
\hline & $\begin{array}{l}\text { Portfolio } \\
\text { Theory }\end{array}$ & $\begin{array}{c}\text { Learning } \\
\text { Commitment }\end{array}$ & $\begin{array}{l}\text { Diverse } \\
\text { Expertise }\end{array}$ & $\begin{array}{c}\text { Open } \\
\text { Mindedness }\end{array}$ & $\begin{array}{c}\text { Portfolio } \\
\text { Diversification }\end{array}$ & MSAs & Communalities \\
\hline LCom1 & & 0.710 & & & & 0.963 & 0.755 \\
\hline LCom2 & & 1.011 & & & & 0.890 & 0.918 \\
\hline LCom3 & & 0.953 & & & & 0.924 & 0.829 \\
\hline LCom4 & & 0.811 & & & & 0.938 & 0.815 \\
\hline LCom5 & & 1.004 & & & & 0.915 & 0.915 \\
\hline EXP1 & & & 0.882 & & & 0.879 & 0.827 \\
\hline EXP2 & & & 1.038 & & & 0.840 & 0.932 \\
\hline EXP4 & & & 0.842 & & & 0.919 & 0.754 \\
\hline OM1 & & & & 0.797 & & 0.914 & 0.515 \\
\hline OM2 & & & & 0.906 & & 0.866 & 0.733 \\
\hline OM3 & & & & 0.784 & & 0.896 & 0.730 \\
\hline OM4 & & & 0.238 & 0.526 & & 0.945 & 0.616 \\
\hline PT1 & 0.822 & & & & & 0.913 & 0.647 \\
\hline PT2 & 0.812 & & & & & 0.905 & 0.641 \\
\hline PT3 & 0.914 & & & & & 0.917 & 0.827 \\
\hline PT4 & 0.871 & & & & & 0.929 & 0.712 \\
\hline PT5 & 0.866 & & & & & 0.937 & 0.738 \\
\hline PT6 & 0.726 & & & & & 0.942 & 0.607 \\
\hline DPort1 & & & & & 0.844 & 0.803 & 0.695 \\
\hline DPort2 & & & & & 0.959 & 0.775 & 0.943 \\
\hline Dport3 & & & & & 0.784 & 0.844 & 0.640 \\
\hline
\end{tabular}

Extraction Method: Principal Axis Factoring. Rotation Method: Promax with Kaiser Normalization. Rotation converged in 5 iterations. MSA is Measure of Sampling Adequacy.

\section{Appendix C}

Table A2. Descriptive Statistics.

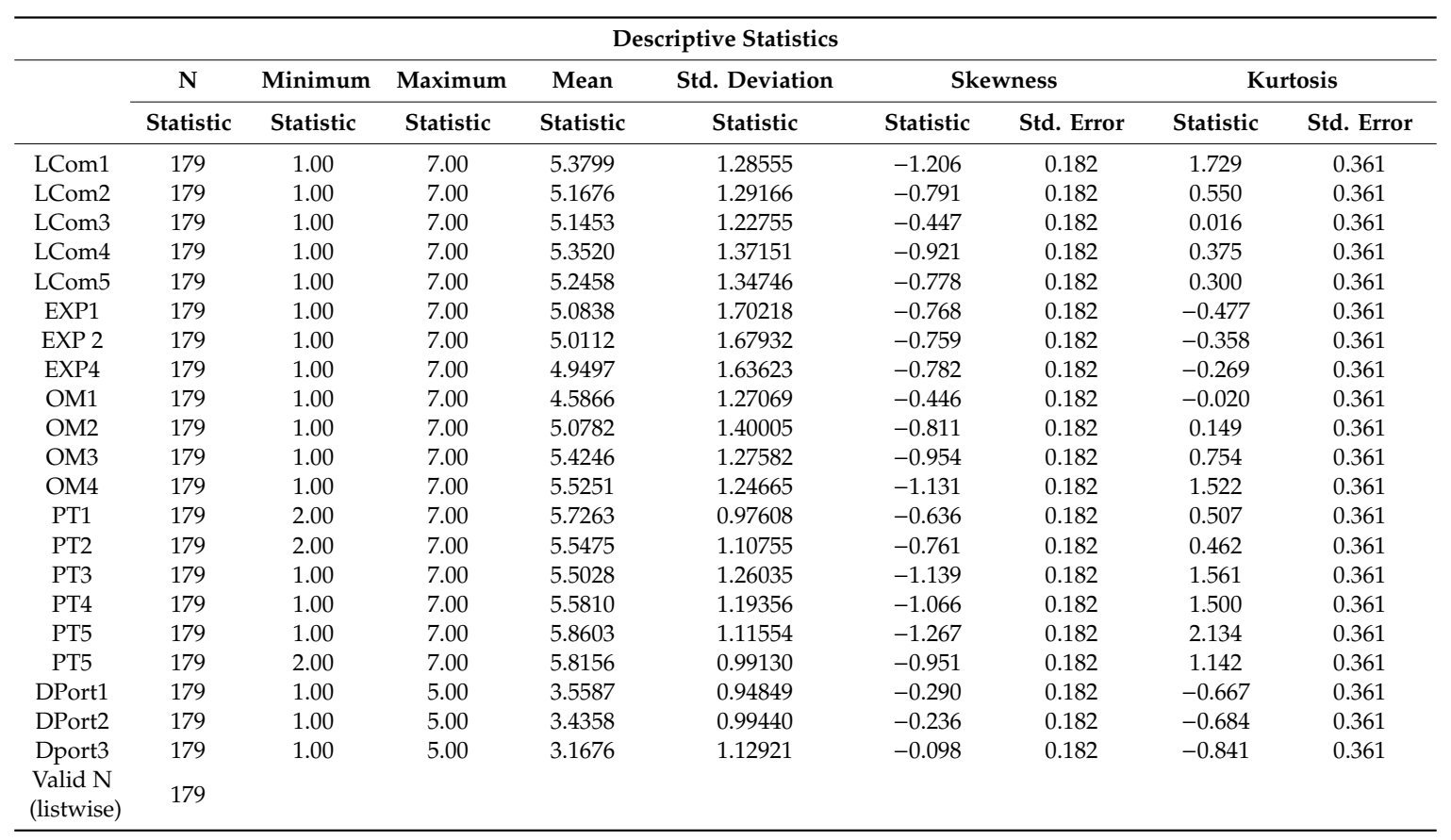

Note: All measures used a 7-point Likert scale except DPort, which used a 5-point scale. 


\section{Appendix D}

Table A3. Correlation of Measures for Constructs.

\begin{tabular}{|c|c|c|c|c|c|c|c|c|c|c|c|c|c|c|c|c|c|c|c|c|c|}
\hline Code & Q2_1 & Q2_2 & Q2_4 & Q1_1 & Q1_2 & Q1_3 & Q1_4 & Q1_5 & Q3_1 & Q3_2 & Q3_3 & Q3_4 & Q8_1 & Q8_2 & Q8_3 & Q8_4 & Q8_5 & Q8_6 & Q6_1 & Q6_2 & Q6_3 \\
\hline Q2_1 & 1 & & & & & & & & & & & & & & & & & & & & \\
\hline Q2_2 & 0.87 & 1 & & & & & & & & & & & & & & & & & & & \\
\hline Q2_4 & 0.78 & 0.83 & 1 & & & & & & & & & & & & & & & & & & \\
\hline Q1_1 & 0.43 & 0.40 & 0.40 & 1 & & & & & & & & & & & & & & & & & \\
\hline Q1_2 & 0.42 & 0.37 & 0.38 & 0.82 & 1 & & & & & & & & & & & & & & & & \\
\hline Q1_3 & 0.38 & 0.35 & 0.39 & 0.75 & 0.88 & 1 & & & & & & & & & & & & & & & \\
\hline Q1_4 & 0.47 & 0.42 & 0.43 & 0.76 & 0.83 & 0.81 & 1 & & & & & & & & & & & & & & \\
\hline Q1_5 & 0.43 & 0.38 & 0.39 & 0.80 & 0.91 & 0.86 & 0.87 & 1 & & & & & & & & & & & & & \\
\hline Q3_1 & 0.29 & 0.24 & 0.30 & 0.45 & 0.34 & 0.33 & 0.38 & 0.34 & 1 & & & & & & & & & & & & \\
\hline Q3_2 & 0.46 & 0.38 & 0.44 & 0.48 & 0.39 & 0.41 & 0.49 & 0.39 & 0.61 & 1 & & & & & & & & & & & \\
\hline Q3_3 & 0.46 & 0.40 & 0.47 & 0.58 & 0.50 & 0.47 & 0.54 & 0.47 & 0.56 & 0.76 & 1 & & & & & & & & & & \\
\hline Q3_4 & 0.56 & 0.52 & 0.54 & 0.57 & 0.44 & 0.46 & 0.53 & 0.46 & 0.56 & 0.57 & 0.64 & 1 & & & & & & & & & \\
\hline Q8_1 & 0.25 & 0.21 & 0.26 & 0.41 & 0.34 & 0.31 & 0.43 & 0.32 & 0.27 & 0.31 & 0.36 & 0.37 & 1 & & & & & & & & \\
\hline Q8_2 & 0.33 & 0.23 & 0.25 & 0.39 & 0.31 & 0.28 & 0.36 & 0.29 & 0.31 & 0.33 & 0.37 & 0.44 & 0.73 & 1 & & & & & & & \\
\hline Q8_3 & 0.40 & 0.34 & 0.36 & 0.46 & 0.38 & 0.33 & 0.40 & 0.37 & 0.33 & 0.40 & 0.45 & 0.48 & 0.69 & 0.74 & 1 & & & & & & \\
\hline Q8_4 & 0.35 & 0.26 & 0.29 & 0.42 & 0.32 & 0.28 & 0.37 & 0.31 & 0.26 & 0.37 & 0.45 & 0.41 & 0.66 & 0.64 & 0.79 & 1 & & & & & \\
\hline Q8_5 & 0.36 & 0.30 & 0.31 & 0.46 & 0.40 & 0.37 & 0.47 & 0.40 & 0.23 & 0.31 & 0.42 & 0.42 & 0.66 & 0.63 & 0.76 & 0.72 & 1 & & & & \\
\hline Q8_6 & 0.39 & 0.33 & 0.39 & 0.43 & 0.36 & 0.33 & 0.42 & 0.37 & 0.29 & 0.34 & 0.48 & 0.44 & 0.58 & 0.57 & 0.70 & 0.64 & 0.74 & 1 & & & \\
\hline Q6_1 & 0.28 & 0.27 & 0.27 & 0.23 & 0.20 & 0.18 & 0.25 & 0.22 & 0.16 * & $0.13^{\text {ns }}$ & $0.17^{*}$ & 0.18 * & 0.23 & 0.19 * & 0.21 & $0.16^{*}$ & 0.22 & 0.18 * & 1 & & \\
\hline Q6_2 & 0.38 & 0.37 & 0.36 & 0.27 & 0.24 & 0.24 & 0.32 & 0.28 & 0.18 * & $0.21^{* *}$ & 0.29 & 0.27 & 0.25 & 0.25 & 0.26 & $0.19^{*}$ & 0.27 & 0.24 & 0.81 & 1 & \\
\hline Q6_3 & 0.33 & 0.34 & 0.30 & $0.21^{* *}$ & $0.21 * *$ & $0.16^{*}$ & 0.30 & 0.24 & 0.17 * & 0.20 * & 0.26 & $0.21^{* *}$ & 0.22 & 0.20 * & $0.19 *$ & $0.13^{\mathrm{ns}}$ & $0.21^{* *}$ & $0.21^{* *}$ & 0.66 & 0.78 & 1 \\
\hline
\end{tabular}

Note: All correlations signifcant at $p<0.001$ except where noted otherwise. $n s=$ nonsignificant. 


\section{Appendix E}

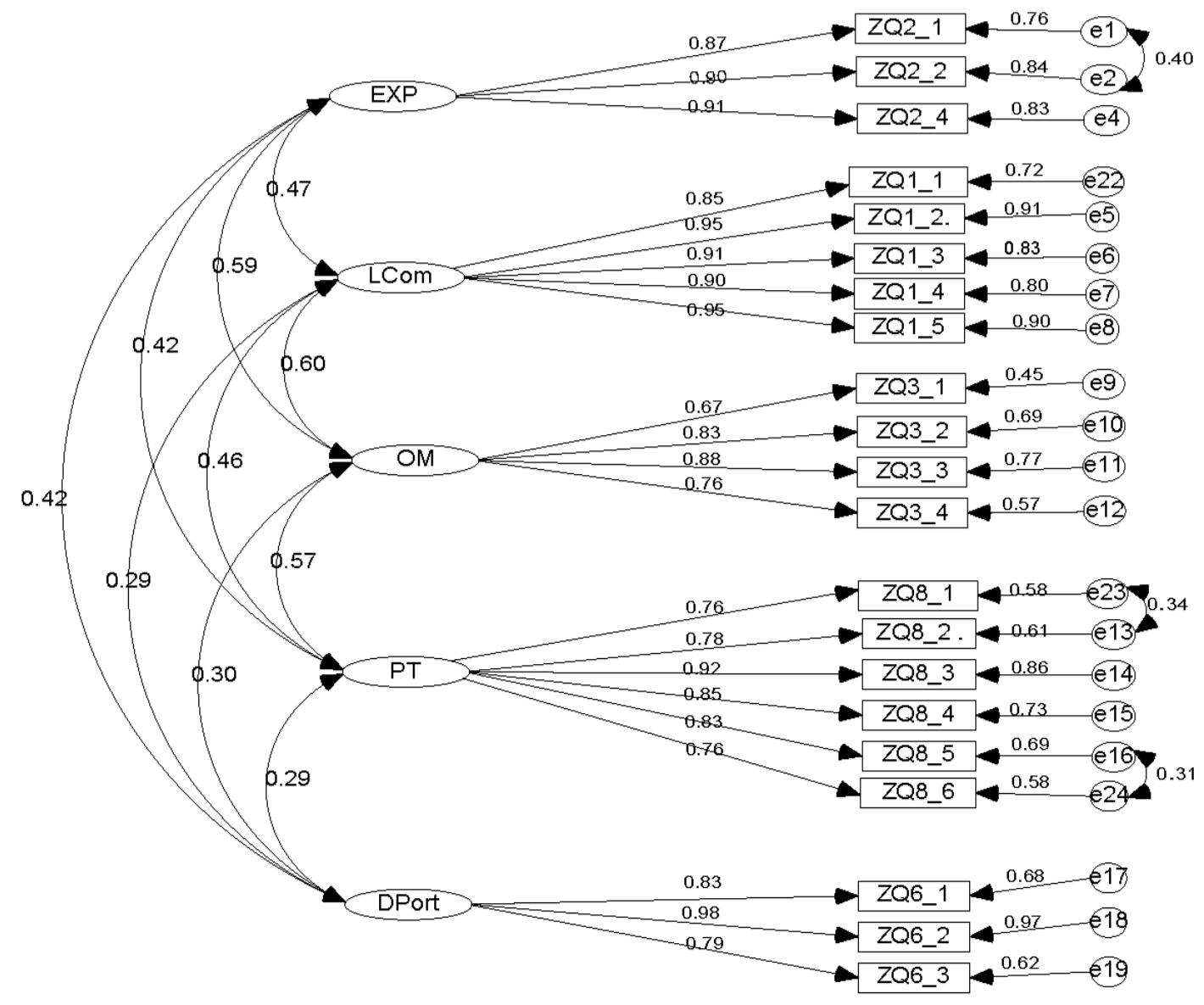

Figure A1. Confirmatory Factor Analysis Model.

\section{References}

Amason, Allen C. 1996. Distinguishing the effects of functional and dysfunctional conflict on strategic decision making: Resolving a paradox for top management teams. The Academy of Management Journal 39: 123-48.

Bär, Michaela, Alexander A. Kempf, and Stefan Ruenzi. 2011. Is a Team Different from the Sum of its Parts? Evidence from Mutual Fund Managers. Review of Finance 15: 359-96. [CrossRef]

Barber, Brad. M., and Terrance Odean. 2008. All that glitters: The effect of attention and news on the buying behavior of individual and institutional investors. The Review of Financial Studies 21: 785-818. [CrossRef]

Barberis, Nicholas, Ming Huang, and Richard H. Thaler. 2006. Individual Preferences, Monetary Gambles, and Stock Market Participation: A Case for Narrow Framing. American Economic Review 96: 1069-90. [CrossRef]

Boynton, Andrew. C., Robert W. Zmud, and Gerry C. Jacobs. 1994. The influence of IT management practice on IT use in large organizations. MIS Quarterly 18: 299-318. [CrossRef]

Brinson, Gary P., L. Randolph Hood, and Gilbert L. Beebower. 1986. Determinants of portfolio performance. Financial Analysts Journal 42: 39-44. [CrossRef]

Brinson, Gary, Brian D. Singer, and Gilbert. L. Beebower. 1991. Determinants of portfolio performance II: An update. Financial Analysts Journal 47: 40-48. [CrossRef]

Brown, Keith C., Lorenzo Garlappi, and Christian I. Tiu. 2010. Asset allocation and portfolio performance: Evidence from university endowment funds. Journal of Financial Markets 13: 268-94. [CrossRef]

Brown, Jeffrey R., Stephen Dimmock, Jun-Koo Kang, David Richardson, and Scott Weisbenner. 2011. The governance of university endowments: Insights from a TIAA-CREF Institute Survey. TIAA-CREF Research Dialogue 101: 1-15. 
Calantone, Roger J., S. Tamer Cavusgil, and Yushan Zhao. 2002. Learning orientation, firm innovation capability, and firm performance. Industrial Marketing Management 31: 515-24. [CrossRef]

Cohen, Wesley M., and Daniel. A. Levinthal. 1990. Absorptive capacity: A new perspective on learning and innovation. Administrative Science Quarterly 35: 128-52. [CrossRef]

Day, George S. 1994. The capabilities of market-driven organizations. Journal of Marketing 58: 37-52. [CrossRef]

Day, George S., and Prakash Nedungadi. 1994. Managerial representations of competitive advantage. Journal of Marketing 58: 31-44. [CrossRef]

DeMiguel, Victor, Lorenzo Garlappi, and Raman Uppal. 2009. Optimal versus naive diversification: How inefficient is the 1/N portfolio strategy? The Review of Financial Studies 22: 1915-53. [CrossRef]

Elton, Edwin J., Martin J. Gruber, Stephen J. Brown, and William N. Goetzmann. 2010. Modern Portfolio Theory and Investment Analysis, 8th ed. Hoboken: John Wiley \& Sons, Inc.

Fabozzi, Frank J., Francis Gupta, and Harry M. Markowitz. 2002. The legacy of modern portfolio theory. The Journal of Investing 11: 7-22. [CrossRef]

Fabozzi, Frank J., Petter N. Kolm, Dessislava Pachamanova, and Sergio M. Focardi. 2007. Robust Portfolio Optimization and Management. Frank J. Fabozzi Series. Hoboken: John Wiley \& Sons, Inc.

Horwitz, Sujin K., and Irwin B. Horwitz. 2007. The effects of team diversity on team outcomes: A meta-analytic review of team demography. Journal of Management 33: 987-1015. [CrossRef]

Forbes, Daniel P., and Frances J. Milliken. 1999. Cognition and corporate governance: Understanding boards of directors as strategic decision-making groups. Academy of Management Review 24: 489-505. [CrossRef]

Francis, Jack C. 2010. Portfolio analysis. In Handbook of Quantitative Finance and Risk Management. Edited by Cheng-Few Lee and John Lee. Part II: 259-66. New York: Springer. [CrossRef]

Garvin, David A. 1993. Building a learning organization. Harvard Business Review 71: 78-91.

Gibson, Roger C. 2004. The rewards of multiple-asset-class investing. Journal of Financial Planning 16: 58-71.

Gibson, Roger C. 2008. Asset Allocation, 4th ed. New York: McGraw-Hill, Inc.

Goetzmann, William N., and Alok Kumar. 2008. Equity portfolio diversification. Review of Finance 12: $433-63$. [CrossRef]

Graham, John R., Campbell R. Harvey, and Hai Huang. 2009. Investor competence, trading frequency, and home bias. Management Science 55: 1094-106. [CrossRef]

Grant, Robert M. 1996. Prospering in dynamically-competitive environments: Organizational capability as knowledge integration. Organization Science 7: 375-87. [CrossRef]

Hair, Joseph F., William C. Black, Barry J. Babin, and Rolph E. Anderson. 2010. Multivariate Data Analysis, 7th ed. Upper Saddle River: Prentice Hall.

Hair, Joseph F., Marcelo Gabriel, and Vijay Patel. 2014. AMOS Covariance-Based Structural Equation Modeling (CB-SEM): Guidelines on Its Application as a Marketing Research Tool. Brazilian Journal of Marketing 13: $44-45$.

Hoffman, L. Richard, and Norman R. F. Maier. 1961. Quality and acceptance of problem solutions by members of homogeneous and heterogeneous groups. Journal of Abnormal and Social Psychology 62: 401-7. [CrossRef] [PubMed]

Ibbotson, Roger G., and Paul D. Kaplan. 2000. Does asset allocation policy explain 40, 90, or 100 percent of performance? Financial Analysts Journal 56: 26-33. [CrossRef]

Janis, Irving L. 1972. Victims of Groupthink. Boston: Houghton-Mifflin.

Jemison, David B., and Sim B Sitkin. 1986. Corporate acquisitions: A process perspective. The Academy of Management Review 11: 145-63. [CrossRef]

Kahneman, David, and Dan Lovallo. 1993. Timid choices and bold forecasts: A cognitive perspective on risk taking. Management Science 39: 17-31. [CrossRef]

Kahneman, David, and Amos Tversky. 2000. Choices, Values and Frames. Cambridge: Cambridge University Press.

Kogut, Bruce, and Udo Zander. 1996. What firms do? Coordination, identity, and learning. Organization Science 7: 502-18. [CrossRef]

Kritzman, Mark, and Sebastien Page. 2003. The hierarchy of investment choice. Journal of Portfolio Management 29: 11-23. [CrossRef]

Kumar, Alok, and Sonya S. Lim. 2008. How do decision frames influence the stock investment choices of individual investors? Management Science 54: 1052-64. [CrossRef]

Leibowitz, Martin L., Anthony Bova, and P. Brett Hammond. 2010. The Endowment Model of Investing. Hoboken: John Wiley \& Sons, Inc. 
Lerner, Josh, Antoinette Schoar, and Jialan Wang. 2008. Secrets of the academy: The drivers of university endowment success. Journal of Economic Perspectives 22: 207-22. [CrossRef]

Lewin, Arie Y., and Henk W. Volberda. 1999. Prolegomena on coevolution: A framework for research on strategy and new organizational forms. Organization Science 10: 519-34. [CrossRef]

Lindell, Michael K., and David J. Whitney. 2001. Accounting for common method variance in cross-sectional research designs. Journal of Applied Psychology 86: 114-21. [CrossRef] [PubMed]

Lord, Mimi. 2014a. Smaller university endowments: Team characteristics, portfolio composition and performance. Qualitative Research in Financial Markets 6: 4-32. [CrossRef]

Lord, Mimi. 2014b. University endowment committees: How a learning orientation and knowledge factors contribute to portfolio diversification and performance. The European Journal of Finance. [CrossRef]

Markowitz, Harry M. 1952. Portfolio selection. The Journal of Finance 7: 77-91.

Markowitz, Harry M. 1959. Portfolio Selection: Efficient Diversification of Investments. New York: John Wiley \& Sons. Mason, Richard O., and Ian I. Mitroff. 1981. Challenging Strategic Planning Assumptions. New York: Wiley.

Michaud, Richard O., and Robert O. Michaud. 2008. Efficient Asset Management. New York: Oxford University Press.

NACUBO. 1990-2008. National Association of College and University Business Officers (NACUBO). NACUBO Endowment Study. Certain Data. Available online: https://www.nacubo.org/Research/2020/HistoricEndowment-Study-Data (accessed on 30 May 2020).

NACUBO. 2009. National Association of College and University Business Officers (NACUBO) \& Commonfund Institute. NACUBO-Commonfund study of endowments. Certain Data. Available online: https://www. nacubo.org/Research/2020/Public-NTSE-Tables (accessed on 30 May 2020).

Podsakoff, Philip M., and Dennis W. Organ. 1986. Self-reports in organizational research: Problems and prospects. Journal of Management 12: 531-44. [CrossRef]

Rubenstein, Mark. 2006. A History of the Theory of Investments. Hoboken: John Wiley \& Sons, Inc.

Scharfstein, David S., and Jeremy C. Stein. 1990. Herd behavior and investment. The American Economic Review 80: 465-79.

Schweiger, David M., and William R. Sandberg. 1989. The utilization of individual capabilities in group approaches to strategic decision-making. Strategic Management Journal 10: 31-43. [CrossRef]

Senge, Peter M. 1990. The Fifth Discipline: The Art and Practice of the Learning Organization. New York: Doubleday.

Sinkula, James M. 1994. Market information processing and organizational learning. Journal of Marketing 58: 35-45. [CrossRef]

Sinkula, James M., William E. Baker, and Thomas Noordewier. 1997. A framework for market-based organizational learning: Linking values, knowledge, and behavior. Journal of the Academy of Marketing Science 25: 305-18. [CrossRef]

Sjoberg, Lennart. 2000. Factors in risk perception. Risk Analysis 20: 1-11. [CrossRef] [PubMed]

Slater, Stanley F., and John C. Narver. 1995. Market orientation and the learning organization. The Journal of Marketing 59: 63-74. [CrossRef]

Smith, Ken A., Satish P. Vasudevan, and Mohan R. Tanniru. 1996. Organizational learning and resource-based theory: An integrative model. Journal of Organizational Change Management 9: 41-53. [CrossRef]

Statman, Meir. 2010. What Investors Really Want: Know What Drives Investor Behavior. New York: McGraw-Hill.

Swensen, David F. 2009. Pioneering Portfolio Management: An Unconventional Approach to Institutional Investing. New York: The Free Press.

Szulanski, Gabriel. 1996. Exploring internal stickiness: Impediments to the transfer of best practice within the firm. Strategic Management Journal 17: 27-43. [CrossRef]

Thaler, Richard. 2005. Advances in Behavioral Finance, Vol. II. Princeton: Princeton University Press.

Tobin, Daniel R. 1993. Re-Educating the Corporation: Foundations for the Learning Organization. Essex Junction: Oliver Wright.

Tversky, Amos, and Daniel Kahneman. 1973. Availability: A heuristic for judging frequency and probability. Cognitive Psychology 5: 207-32. [CrossRef]

Wadhwa, Anu, and Suresh Kotha. 2006. Knowledge creation through external venturing: Evidence from the telecommunications equipment manufacturing industry. Academy of Management Journal 49: 819-35. [CrossRef] 
Weber, Elke U., Niklas Siebenmorgen, and Martin Weber. 2005. Communicating asset risk: How name recognition and the format of historic volatility information affect risk perception and investment decisions. Risk Analysis 25: 597-609. [CrossRef]

Zahra, Shaker, and Gerard George. 2002. Absorptive capacity: A review, reconceptualization, and extension. Academy of Management Review 27: 185-203. [CrossRef] 